\title{
DESENVOLVIMENTO DE SORVETE BIOFORTIFICADO COM CARACTERISTICAS FUNCIONAIS
}

\section{DEVELOPMENT OF BIOFORTIFIED ICE CREAM WITH FUNCTIONAL CHARACTERISTICS}

\author{
Fabiane Ribeiro Teixeira ${ }^{1}$, Silmara Dayane Fiorentin ${ }^{1}$, Sabrine Zambiazi da Silva ${ }^{2 *}$, \\ Daniela Miotto Bernardi ${ }^{3}$, Frederico Rodrigues Lovato ${ }^{4}$ \\ ${ }^{1}$ Nutricionista, Especialista, Centro Universitário da Fundação Assis Gurgacz (FAG). ${ }^{2}$ Nutricionista. \\ Mestre, Docente do curso de Nutrição, Centro Universitário da Fundação Assis Gurgacz (FAG). \\ ${ }^{3}$ Nutricionista, Doutora, Docente do curso de Nutrição, Centro Universitário da Fundação Assis \\ Gurgacz (FAG). ${ }^{4}$ Engenheiro Químico, FUNDETEC, Cascavel - PR. \\ *Autor correspondente: sazambiazi@yahoo.com.br, https://orcid.org/0000-0001-6931-3601
}

\section{RESUMO}

Sorvete é um alimento consumido por todas as faixas etárias e classes sociais, oferecido em variados sabores e combinações. O trabalho teve como objetivo produzir um sorvete com batata doce biofortificada Beauregard avaliando as características físicos químicas e funcionais. Foram produzidas três formulações, sendo F1 (Padrão, sem batata doce), F2 (batata doce convencional) F3 (batata doce Beauregard). Após processamento as amostras de sorvete foram armazenadas sob congelamento ( $\left.-4^{\circ} \mathrm{C}\right)$. Em seguida foram realizadas análises físico-químicas, microbiológica e sensorial das amostras. Em $100 \mathrm{~g}$ das amostras foram encontrados os seguintes resultados: $\mathrm{F} 1$ : carboidrato $63 \mathrm{~g}$, proteína $3,3 \mathrm{~g}$, lipídio $12 \mathrm{~g}$, ferro $0,93 \mathrm{mg}$, umidade $65 \%$, betacaroteno $5,7 \mathrm{mcg}$, fibra1,9g, F2: carboidrato $55,1 \mathrm{~g}$, proteína 3,78g, lipídio $6,9 \mathrm{~g}$, ferro $0,9 \mathrm{mg}$, umidade $65,48 \%$, betacaroteno $20,9 \mathrm{mcg}$, fibra $3,1 \mathrm{~g}$, F3: carboidrato $57,6 \mathrm{~g}$, proteína $4,16 \mathrm{~g}$, lipídio $8,01 \mathrm{~g}$, ferro $0,12 \mathrm{mg}$, umidade $63,4 \mathrm{~g}$, betacaroteno $53,6 \mathrm{mcg}$, fibra $2,2 \mathrm{~g}$. As análises microbiológicas apresentaram resultados de ambas as amostras: Coliformes Totais(NMP/g) <3,0, Coliformes Termotolerantes(NMP/g) <3,0, Staphylococcus aureus(UFC/g) $<10^{2}$, Salmonella(/25g) ausência. Participaram da análise sensorial 138 julgadores não treinados, a aceitabilidade foi similar para todas as formulações em relação aos atributos aparência, aroma, sabor, textura, com nota igual ou superior a 7. Pode-se concluir que é possível elaborar um produto saudável e de boa aceitabilidade com batata doce Beauregard.

Palavras-chaves: funcional; biomassa; Beauregard;

\begin{abstract}
Ice cream is a food consumed by all age groups and social classes, offered in various flavors and combinations. The objective of the work was to produce an ice cream with biofertified sweet potato Beauregard evaluating the physical and chemical characteristics. Three formulations were produced, being F1 (Standard, no sweet potato), F2 (conventional sweet potato) F3 (sweet potato Beauregard). After processing the ice cream samples were stored under freezing $\left(-4^{\circ} \mathrm{C}\right)$. Then, the physico-chemical, microbiological and sensorial analyzes of the samples were performed. In $100 \mathrm{~g}$ of the samples the following results were found: F1: carbohydrate $63 \mathrm{~g}$, protein $3.3 \mathrm{~g}$, lipid $12 \mathrm{~g}$, iron $0.93 \mathrm{mg}$, humidity $65 \%$, betacarotene $5.7 \mathrm{mcg}$, fiber1,9g, F2: carbohydrate 55,1g, protein $3,78 \mathrm{~g}$, lipid $6.9 \mathrm{~g}$, iron $0.9 \mathrm{mg}$, moisture $65.48 \%$, betacarotene $20.9 \mathrm{mcg}$, fiber $3.1 \mathrm{~g}$, F3: carbohydrate $57.6 \mathrm{~g}$, protein $4.16 \mathrm{~g}$, lipid
\end{abstract}


8.01g, iron $0.12 \mathrm{mg}, 63.4 \mathrm{~g}$ moisture, $53.6 \mathrm{mcg}$ betacarotene, $2.2 \mathrm{~g}$ fiber. Microbiological analyzes showed results of both samples: Total Coliforms (NMP / g) <3.0, Thermotolerant Coliforms (NMP / g) <3.0, Staphylococcus aureus (UFC / g) <102, Salmonella. In the sensory analysis of 138 untrained judges, the acceptability was similar for all formulations with respect to attributes appearance, aroma, flavor, texture, with a grade equal or superior to 7 . It can be concluded that it is possible to elaborate a healthy product and good acceptability with sweet potato Beauregard.

Keywords: functional; biomass; Beauregard.

\section{INTRODUÇÃO}

Pode-se destacar que, a ingestão de 25 a $50 \mathrm{~g}$ de batata biofortificada Beauregard é capaz de suprir às quantidades diárias recomendadas de pró-vitamina A (EMBRAPA, 2015).

A vitamina $A$ é destacada como um nutriente fundamental à conservação dos papéis fisiológicos do organismo, portanto é associada à diminuição de mortes de crianças no primeiro ano de vida e também das mães, diminuição do risco de infecções, assim como a infecção respiratória aguda e diarréia, a preservação da visão e dos olhos, e é essencial para a saúde infantil, assim como o seu crescimento e desenvolvimento (BRASIL, 2012b). A carência é considerada problema de saúde pública.

Destaca-se que, a carência de vitamina A é uma das deficiências nutricionais mais predominantes nos países que estão em fase de desenvolvimento e ataca especialmente crianças em uma faixa de 5 meses a 6 anos de idade, ocasionando implicações inconvertível (BRASIL, 2012b). É considerado um micronutriente significativo, por seu papel na integridade cutânea, defesa de estruturas e desempenhos oculares, sistema imunológico e redução da morbimortalidade por doenças infecciosas, como diarréia, sarampo e malária. Sua deficiência resulta em disfunções oculares como xeroftalmia e cegueira noturna (QUEIROZ et al.,2013).

Portanto, o objetivo desse trabalho foi produzir um sorvete a partir de batata doce biofortificada Beauregard e avaliar as características físicas, químicas e funcionais.

\section{METODOLOGIA}

\subsection{MATÉRIA PRIMA}

A batata doce da variedade Beauregard foi cedida pela Fundação para o Desenvolvimento Cientifico e Tecnológico (FUNDETEC), localizada na cidade de Cascavel- PR. Os demais ingredientes, batata doce convencional, água, goma xantana, biomassa de banana verde, açúcar demerara orgânico, leite em pó, coco, leite de coco, e iogurte de coco utilizados na elaboração das formulações dos sorvetes foram adquiridos no comércio local.

\subsection{FORMULAÇÕES}

Foram testadas três formulações de sorvete, cujos ingredientes e as quantidades utilizadas estão indicados na Tabela 1. 
Tabela 1. Formulação das amostras de sorvete

\begin{tabular}{|c|c|c|c|}
\hline INGREDIENTES & F1\% * & F2\% * & F3\% * \\
\hline Água & 30,4 & 26,4 & 26,4 \\
\hline Goma xantana & 0,3 & 0,3 & 0,3 \\
\hline Biomassa de banana verde ${ }^{\star *}$ & 4,6 & 4,0 & 4,0 \\
\hline Açúcar demerara & 7,6 & 6,6 & 6,6 \\
\hline Leite em pó & 11,4 & 9,9 & 9,9 \\
\hline Batata doce convencional $^{\star *}$ & 0 & 13,2 & 0 \\
\hline Batata doce biofortificada ${ }^{* *}$ & 0 & 0 & 13,2 \\
\hline Coco fresco & 6,1 & 5,3 & 5,3 \\
\hline Leite de coco & 9,1 & 8,0 & 8,0 \\
\hline $\begin{array}{l}\text { logurte parcialmente desnatado de } \\
\text { coco }\end{array}$ & 30,4 & 26,4 & 26,4 \\
\hline
\end{tabular}

${ }^{\star}$ F1 (formulação do sorvete sem adição de batata doce) F2 (modificação da formulação padrão com adição de batata doce convencional) F3 (modificação da formulação padrão com adição de batata biofortificada).

${ }^{* *}$ Porcentagem corresponde a matéria prima cozida.

\subsection{HIGIENIZAÇÕES DAS MATÉRIAS PRIMAS E EQUIPAMENTOS}

Iniciou-se com a pré-higienização das bancadas, onde seria desenvolvido o produto, com água clorada e álcool $70 \%$. Foram selecionadas as batatas e as bananas verdes, enxaguadas em água corrente para a remoção de sujidades, posteriormente foram deixadas submersas em bandejas individuais em solução de água clorada a 200 ppm por 15 minutos e enxaguadas novamente em água corrente. Os utensílios utilizados, tais como colheres, facas, garfos, liquidificador, batedeira, e panelas também foram submersos em água clorada a 200 ppm por 15 minutos, para garantir uma qualidade higiênica sanitária favorável. Foram utilizados copos e pratos descartáveis para facilitar a organização e minimizar riscos de contaminação.

\subsection{ELABORAÇÃO}

Após ter sido realizada a higienização dos utensílios, foi colocada para cozinhar a batata doce beauregard e a batata doce convencional por 40 minutos em $250^{\circ} \mathrm{C}$, e a banana verde orgânica por 25 minutos em $200^{\circ} \mathrm{C}$ para a realização da biomassa. Com as batatas doces foi realizado um purê em pratos individuais para cada espécie.

Os ingredientes foram pesados em uma balança de precisão (Marte AS2000C) e medidos em copo medidor.

Em um liquidificador (Britânia Diamante Black Filter4 Velocidades 600W Preto - 110V) foi acrescentado a água e a goma xantana, homogeneizadas por 2 minutos, até formar uma consistência de gel. Após esse procedimento, foram adicionados os demais ingredientes seguindo uma sequência:

Biomassa $->$ açúcar $->$ leite em pó $->$ batata doce específica para cada formulação -> coco -> leite de coco -> logurte de coco e liquidificados os produtos em temperatura ambiente.

Essa mistura foi imediatamente colocada dentro de potes descartáveis, de 1L, etiquetadas com o tipo de amostra (biofortificada, convencional e padrão) e levadas para maturação em $4^{\circ} \mathrm{C}$, por 24 horas em um refrigerador industrial. Na maturação a massa necessita de refrigeração a $4^{\circ} \mathrm{C}$ para que não tenha desenvolvimento de bactérias e acréscimo exagerado da viscosidade do sorvete (SOLER; VEIGA, 2001). Após a maturação, procedeu-se o congelamento, desempenhada junto com 0 
batimento do sorvete, nessa etapa acontece à incorporação de ar chamado de overrun (MADRID; CENZANO; VICENTE, 1995). Posteriormente, o sorvete foi acondicionado a congelamento em $-4^{\circ} \mathrm{C}$. No congelamento é essencial que o procedimento seja rápido, garantindo dessa forma pequenos cristais de gelo que atribuem característica cremosa típica do sorvete (NARAIN et al., 2006).

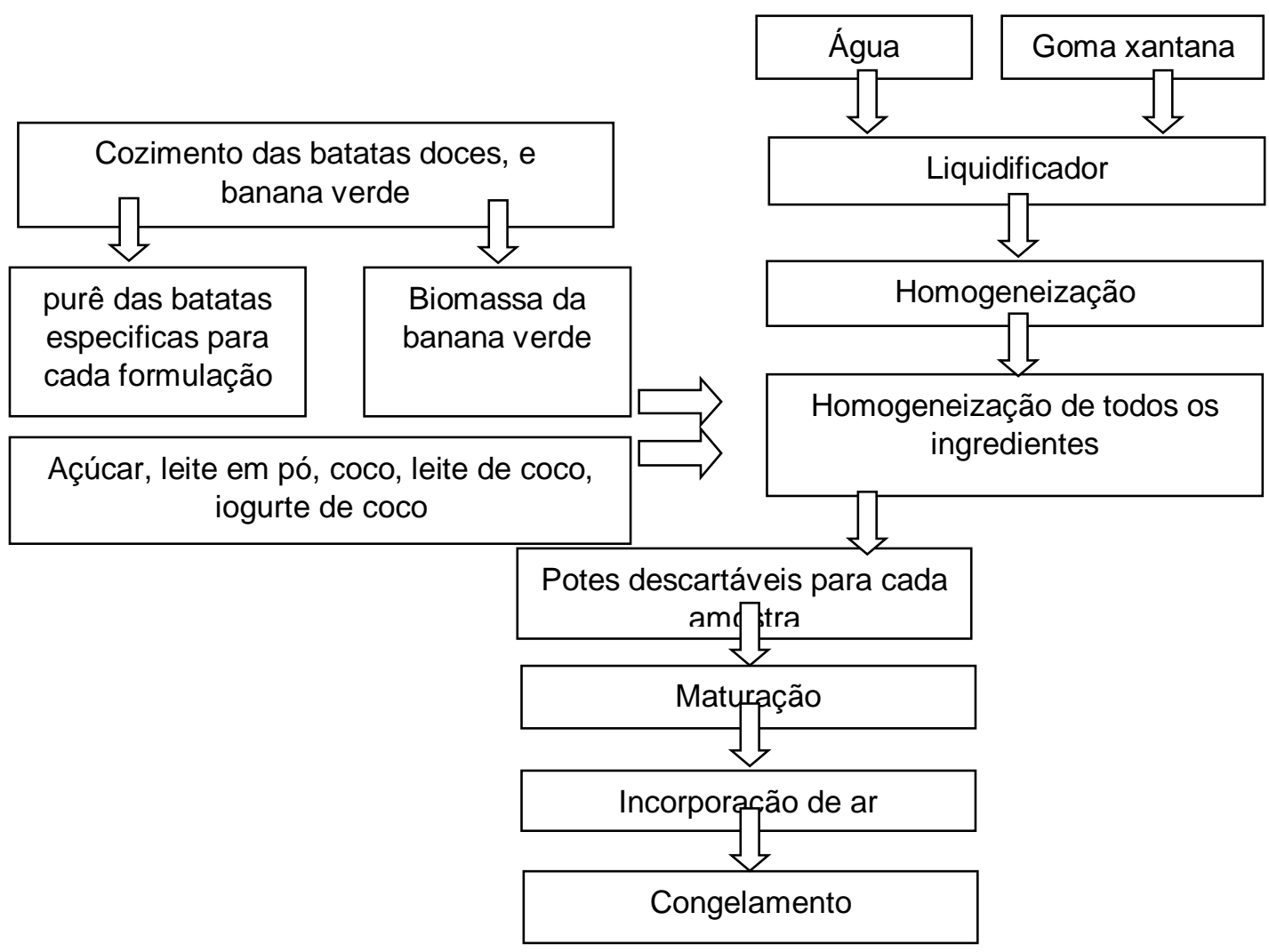

Figura 1. Fluxograma geral do processamento do sorvete

\subsection{ANÁLISES MICROBIOLÓGICAS E FÍSICO-QUÍMICAS}

As análises microbiológicas foram feitas pelo laboratório da Fundação para o Desenvolvimento Cientifico e Tecnológico-FUNDETEC, localizada na cidade de Cascavel-PR. As análises realizadas foram Contagem de Coliformes Termotolerantes, Coliformes Totais, Escherichia coli, Staphylococcus aureus coagulase positiva e análise de Salmonella SP seguindo a metodologia Compendium of Methods for the Microbiological examination of foods, (2001).

As análises físico-químicas foram feitas pelo laboratório da Fundação para o Desenvolvimento Cientifico e Tecnológico-FUNDETEC. As análises realizadas foram carboidratos por diferença, proteínas, lipídios, fibras, vitamina A, umidade e cinzas e ferro, seguindo as metodologias descritas pelas Normas Analíticas do Instituto Adolfo Lutz (Instituto Adolfo Lutz ,2008).

\subsection{ANÁLISE SENSORIAL}

Antes da pesquisa ser desenvolvida, ela foi submetida por avaliação do comitê de ética em pesquisa com humanos e recebeu parecer favorável nْ1.879.793. Após, os participantes, foram convidados a ler e assinar o Termo de consentimento livre e esclarecido (TCLE). 
A análise foi realizada em cabines específicas para esse tipo de trabalho. A porção entregue a cada participante foi de 10 gramas de sorvete de cada formulação, servido de forma individual, comum copo de água para remoção do sabor residual de cada amostra, foi codificado com números aleatórios de três dígitos (WALKELING; MACFIE, 1995).Utilizou-se o formulário de escala de 9 pontos (MEILGAARD et al, 1999),considerando para escala de aceitação o atributo (1) desgostei muitíssimo e (9) gostei muitíssimo. Além disso, foi avaliada a intenção de compra do consumidor por meio de uma escala estruturada de 5 pontos (1) certamente não compraria, e (5) certamente compraria (DUTCOSKY, 2013). As amostras foram servidas de forma monádica em blocos completos aleatorizados (MACFIE et al, 1989).

As amostras foram servidas na temperatura de $-4^{\circ} \mathrm{C}$.

\subsection{ANÁLISE ESTATÍSTICA}

Os dados referentes à aceitação das 3 amostras foram submetidos a uma análise de variância (ANOVA) e ao teste Tukey, considerando nível de significância de $5 \%$ para identificar a diferença entre as formulações, em um programa Microsoft Excel.

\section{RESULTADOS E DISCUSSÃO}

\subsection{COMPOSIÇÃO QUÍMICA}

Foi realizada a análise física-química das três formulações de sorvete, cujos resultados estão indicados na Tabela 2.

Tabela 2. Resultados da análise físico química das três formulações do sorvete.

\begin{tabular}{lllll}
\hline NUTRIENTE & & $\mathrm{F}^{*}$ & & $\mathrm{~F}{ }^{*}{ }^{*}$ \\
\hline Umidade $(\%)$ & 65 & 65,48 & 63,4 & \\
Ptn $(\mathrm{g} / 100 \mathrm{~g})$ & 3,3 & 3,78 & 4,16 & \\
Lip $(\mathrm{g} / 100 \mathrm{~g})$ & 12 & 6,9 & 8,01 \\
Cho $(\mathrm{g} / 100 \mathrm{~g})$ & 63 & 55,1 & 57,6 \\
Fibra $(\mathrm{g} / 100 \mathrm{~g})$ & 1,9 & 3,1 & 2,2 \\
Cinzas $(\mathrm{g} / 100 \mathrm{~g})$ & 1,09 & 20,9 & 1,10 \\
Betacaroteno & 5,7 & & 53,6 \\
(mcg/100g) & & 0,9 & \\
Ferro (mg/100g) & 0,93 & & 0,12 \\
\hline
\end{tabular}

${ }^{*} \mathrm{~F} 1$ (formulação do sorvete sem adição de batata doce) F2 (modificação da formulação padrão com adição de batata doce convencional) F3 (modificação da formulação padrão com adição de batata biofortificada).

De acordo com a Tabela de composição de alimentos IBGE (2011), 100 gramas de sorvete de qualquer sabor industrializado possuem 25,13 gramas de carboidrato 3,60 gramas de proteína, 11 gramas de lipídeo e 0,87 gramas de fibras. Comparando esses valores com a pesquisa, os teores de fibras das amostras F1 $(1,9 g)$ F2 $(3,1 \mathrm{~g})$ e F3 $(2,2 \mathrm{~g})$ são superiores. Segundo a ANVISA, para que um alimento seja considerado fonte de fibras alimentares, o produto deve fornecer 3 gramas de fibras, caso seja um alimento sólido, ou 1,5 gramas, em caso de alimento líquido (ANVISA). Os valores de proteína se encontram similares em F1 $(3,3 \mathrm{~g})$ e F2 $(3,78 \mathrm{~g})$, F3 $(4,16 \mathrm{~g})$, é destacado um valor superior em comparação com a tabela IBGE. Em relação ao lipídeo $\mathrm{F} 1$ aponta um valor maior que o sorvete industrializado, mas vale ressaltar que, nas três formulações, não houve adição de gordura hidrogenada, a 
gordura presente é proveniente do coco, leite de coco, e demais ingredientes utilizados. O carboidrato está elevado nas três formulações em comparação com o sorvete industrializado, isso porque a batata doce, o leite em pó e demais ingredientes, contém grande quantidade desse macronutriente.

A indicação de betacaroteno pode ser evidenciada pela forma de acondicionamento, bem como, o tempo em que o produto ficou armazenado durante 40 dias até a realização das análises, e até mesmo pela incorporação de alguns ingredientes e distintas reações químicas.

Segundo Gregory (2010) a deterioração de retinoides carotenóides com atividade pró-vitamina A, costuma ser comparada à degradação de gorduras insaturadas. Em contato com o oxigênio, os hidroperóxidos que procedem das reações de autoxidação dos ácidos graxos polinsaturados acabam descolorindo os carotenóides e retinoides. Os produtos que passam por um processo de desidratação com uma ampla região superficial exposta, em contato com oxigênio, têm rompimento acelerado dos carotenóides de acordo com Coultate (2004).

Para Gregory (2010) na maior parte das ocasiões, a composição de retinoides e carotenóides continuam ilesos durante o tratamento térmico, porém, pode ocorrer isomerização. A exibição à luz durante o acondicionamento pode desempenhar implicação na retenção da vitamina $A$ em produtos, acontecendo reações de deterioração fotoquímicas.

Segundo Soares e Craft (1992) o emprego de betacaroteno em produtos é restringida pela pequena solubilidade em soluções aquosas, pois se trata de um componente lipofílico, e também devido à instabilidade química. Por esse motivo não é indicado ser adicionado em preparações com base aquosa.

Para Ribeiro et al (2003) e Kispert e Polyakov (2010), o pH é um dos fatores que pode ter influência na estabilidade do betacaroteno. Foi constatado que a degradação tem início por agentes pro - oxidantes, o ferro é um mineral que está contido em vários alimentos e tem sido apontado como um micronutriente de degradação do betacaroteno, sendo aumentada em pH baixo, pois a solubilidade do ferro é aumentada.

Segundo Faraji et al (2004) e Chen et al (2010), o betacaroteno tem interação com agentes emulsificantes podendo originar barreira física e eletrostática para os metais de transição e outros agentes pro - oxidantes presentes na composição do alimento.

Britton (1992) diz que a estrutura do carotenóide, a quantidade de oxigênio disponível, a atividade de água, o grau de luminosidade, a temperatura, o pH, a presença de antioxidantes, pro oxidantes, ácidos graxos e sulfitos interferem na degradação do carotenóide.

O Desenvolvimento de uma planta e suas características podem sofrer alterações, pela época do cultivo, de acordo com Mustonen et al (2010), pelo manejo da cultura, segundo Geremew et al (2007) e devido à fertilização nitrogenada, segundo Zebarth e Rosen (2007). Vale ressaltar que os níveis de micronutrientes podem ter sido reduzidos devido a uma má safra.

A umidade das amostras variou entre 65, 65,48 e 63\% resultados similares são citados no estudo de Rossa (2008), que encontrou valores de umidade variando entre 61,53 e $67,30 \%$ ao analisar amostras de sorvetes de morango, baunilha e chocolate. 


\subsection{ANÁLISE MICROBIOLÓGICA}

Tabela 3.

Foi realizada análise microbiológica cujos resultados estão representados na

Tabela 3. Resultados da Análise Microbiológica das três formulações do sorvete (a $100 \mathrm{~g}$ do produto)

\begin{tabular}{llll}
\hline Microorganismo & $\mathrm{F} 1$ & $\mathrm{~F} 2$ & $\mathrm{~F} 3$ \\
\hline Coliformes Totais (NMP/g) & $<3,0$ & $<3,0$ & $<3,0$ \\
Coliformes Termotolerantes (NMP/g) & $<3,0$ & $<3,0$ & $<3,0$ \\
Staphylococcus aureus (UFC/g) & $<10^{2}$ & $<10^{2}$ & $<10^{2}$ \\
Salmonella (/25g) & Ausência & Ausência & Ausência \\
\hline
\end{tabular}

${ }^{*}$ F1 (formulação do sorvete sem adição de batata doce) F2 (modificação da formulação padrão com adição de batata doce convencional) F3 (modificação da formulação padrão com adição de batata biofortificada).

Os resultados da análise microbiológica mostram que os índices de microorganismos estão de acordo em relação aos valores estabelecidos pela legislação vigente RDC 12/2001.

\subsection{ANÁLISE SENSORIAL}

Participaram da pesquisa 138 julgadores não treinados, de ambos os gêneros, com idade de 12 a 48 anos com idade média de 22,7 $\pm 5,28$.

Em relação ao registro de avaliação sensorial sobre os atributos aceitação global, aparência, aroma sabor e textura para F1, F2 e F3, os resultados estão apontados na Tabela 4.

Tabela 4. Resultados da escala de aceitação para as três formulações de sorvete

\begin{tabular}{lllll}
\hline & $\mathrm{F}^{*}$ & $\mathrm{~F} 2^{*}$ & $\mathrm{~F} 3^{*}$ & $\mathrm{p}$ \\
\hline AG & $7,34 \pm 1,40$ & $7,17 \pm 1,59$ & $7,23 \pm 1,44$ & 0,348 \\
AP & $7,61 \pm 1,40$ & $7,35 \pm 1,45$ & $7,46 \pm 1,40$ & 0,123 \\
ARO & $7,30 \pm 1,51 \mathrm{AB}$ & $7,06 \pm 1,68 \mathrm{~B}$ & $7,41 \pm 1,40 \mathrm{~A}$ & 0,036 \\
SAB & $7,24 \pm 1,67$ & $6,93 \pm 1,98$ & $7,17 \pm 1,72$ & 0,110 \\
TEX & $7,22 \pm 1,72$ & $6,94 \pm 1,75$ & $6,99 \pm 1,79$ & 0,135 \\
\hline
\end{tabular}

*F1 (formulação do sorvete sem adição de batata doce) F2 (modificação da formulação padrão com adição de batata doce convencional) F3 (modificação da formulação padrão com adição de batata biofortificada).

Letras na mesma linha indicam que existe diferença estatística entre as amostras a 5\% de significância, segundo o teste de Tukey.

As amostras tiveram boa aceitabilidade, pois a média das notas para todos os atributos, aceitação global, aparência, aroma, sabor e textura foram iguais ou acima de sete, poucas situações foram inferiores, sete é uma linha de demarcação de boa aceitação pelos consumidores. Então as amostras foram bem aceitas e isso é um resultado positivo, o que foi observado é que a produção de um sorvete com batata doce biofortificada em comparação com o sorvete padrão não interferem nos atributos de maneira geral, porém interferiram sim em relação ao aroma. Foi verificado que a amostra biofortificada (F3) foi a que apresentou melhor aroma das demais e que a 
convencional (F2) foi a que apresentou pior aroma, e a padrão (F1) teve aroma estatisticamente igual tanto a biofortificada quanto a padrão, ou seja não diferiu.

Em relação ao registro de avaliação sensorial sobre os atributos de intenção de compra, certamente compraria, provavelmente compraria, tenho duvida se compraria ou não, provavelmente não compraria, e certamente não compraria para as formulações F1, F2 e F3, os resultados estão apontados abaixo na Figura 1.

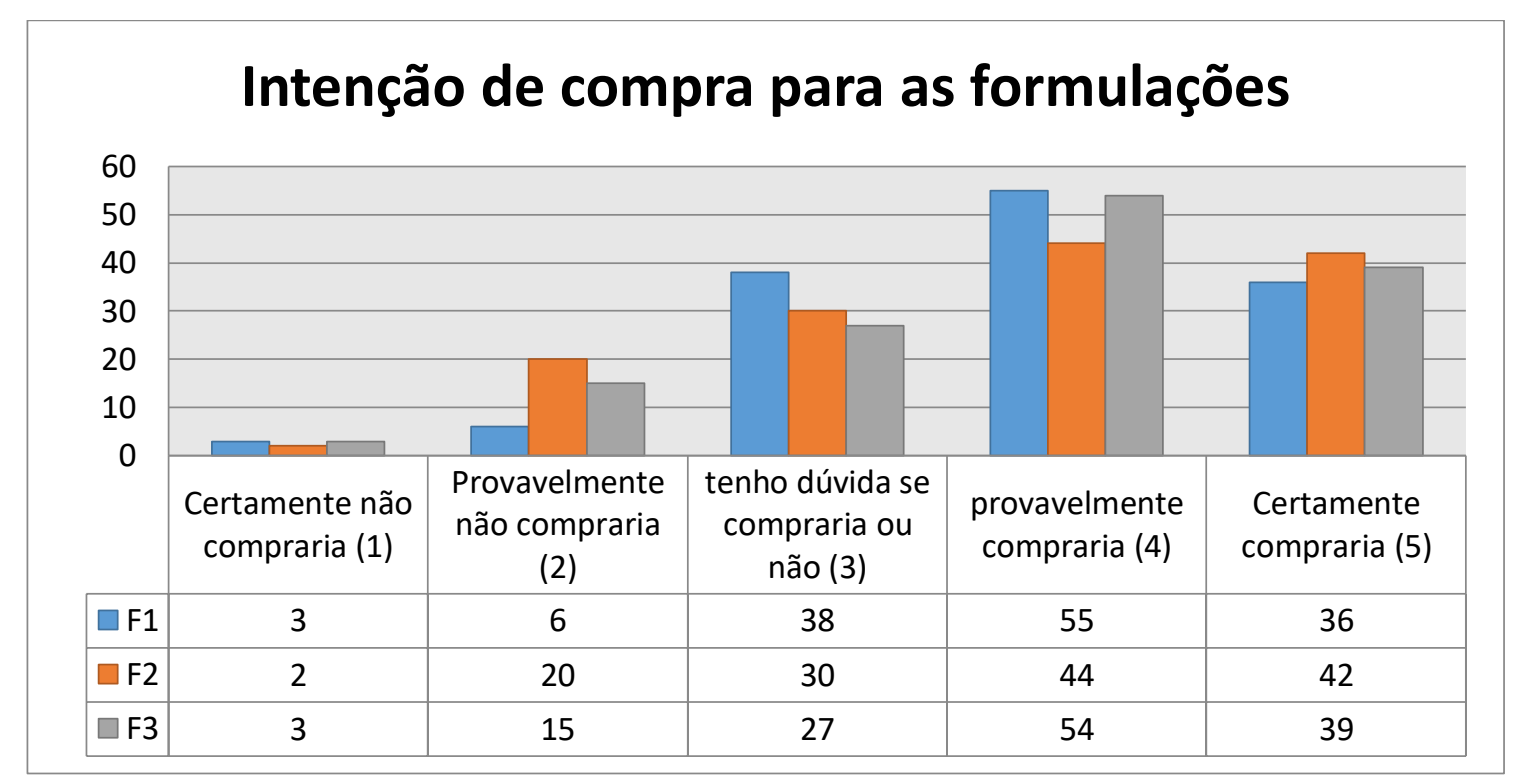

Figura 2. Histograma indicando a intenção de compra das três amostras de sorvete. ${ }^{*} \mathrm{~F} 1$ (formulação do sorvete sem adição de batata doce) F2 (modificação da formulação padrão com adição de batata doce convencional) F3 (modificação da formulação padrão com adição de batata biofortificada).

É observado que todas as amostras tiveram boa aceitação, pois provavelmente compraria se destaca predominante no histograma.

E certamente não compraria é o índice mais baixo na avaliação, e pode ter sido julgado devido à aversão a coco ou qualquer outro ingrediente utilizado, assim como redução de açúcares e gorduras na composição.

\section{CONCLUSÃO}

Foi possível elaborar um produto saudável, com paladar agradável, e com valor de fibras maior do que os já existentes no mercado, porém, verificou-se que o teor de betacaroteno pode ter sido prejudicado na F3 devido a fatores como luz, ph, solução aquosa, interação entre nutrientes, emulsificantes, bem como oxidação do produto.

\section{REFERÊNCIAS}

ANVISA. Agencia Nacional de Vigilância Sanitária. Portal online da ANVISAAlegações de Propriedade Funcional Aprovadas. Disponível em: $<$ http://portal.anvisa.gov.br/wps/content/Anvisa+Portal/Anvisa/Inicio/Alimentos/Assun tos+de+Interesse/Alimentos+Com+Alegacoes+de+Propriedades+Funcionais+e+ou+ $\mathrm{de}+$ Saude/Alegacoes+de+propriedade+funcional+aprovadas $>$ Acesso

em: 22/06/2017. 
BRASIL, Ministério da Saúde. Política Nacional de Alimentação e Nutrição: Programa Nacional de Suplementação de Vitamina A. Brasília, DF, 2012.

CHEN, B.; McCLEMENTS, D. J.; DECKER, E. A. Role of Continuous Phase Anionic Polysaccharides on the Oxidative Stability of Menhaden Oil-in-Water Emulsions. Journal of Agricultural and Food Chemistry, 58, 3779-3784, 2010.

American Public Health Association Compendium of Methods for the Microbiological Examination of Foods. 4ํe․ Cap. 8. Washington: (APHA), 2001.

DUTCOSKY, S. D. Análise sensorial de alimentos. 4 ed. rev. e. ampl. - Curitiba PR. Editora Champagnat, 2013.

EMBRAPA.Batata-Doce Beauregard. A batata vitaminada. Disponível em: $<$ http://www.cnph.embrapa.br/paginas/produtos/cultivares/batata_doce_beauregard. html> Acesso: 09 maio 2017.

FARAJI, H.; McCLEMENTS, D. J.; DECKER, E. A. Role of continuous phase protein on the oxidative stability of fish oil-in-water emulsions. Journal of Agricultural and Food Chemistry, 52, 4558-4564, 2004.

FREITAS, M. C. J.; TAVARES, D. Q. Caracterização do grânulo de amido de bananas. Ciência e Tecnologia de Alimentos, v. 25, n.02, p. 217-222, 2012.

GEREMEW, E.B.; STEYN, J.M.; ANNANDALE, J. G. Evaluation of growth performance and dry matter partitioning of four processing potato (Solanum tuberosum) cultivars. New Zealand Journal of Cropand Horticultural Science. v.35, p.385- 393, 2007.

IBGE. Instituto Brasileiro de Geografia e Estatística. Pesquisa de orçamentos familiares-POF, 2008-2009: análise do consumo alimentar pessoal no Brasil. Coordenação de Trabalho e Rendimento. Rio de Janeiro: IBGE; 2011

INSTITUTO ADOLFO LUTZ. Normas Analíticas do Instituto Adolfo Lutz.v. 1: Métodos químicos e físicos para análise de alimentos, 4aㅡ ed. São Paulo, cap.IV. p. 813-814, 2008.

KISPERT, L. D.; POLYAKOV, N. E. Carotenoid radicals: Cryptochemistry of natural colorants.Chemistry Letters, 39, 148-155, 2010.

MACFIE, H. J.; BRATCHELL, N.; GREENHOFF, K.; VALLIS, L. Projeto para equilibrar o efeito da ordem de apresentação e de primeira ordem efeitos carryover em testes de salão. Revista de Estudos Sensoriais, Westport, v. 4, n. 2, p. 129148, 1989.

MADRID, A.; CENZANO, I.; VICENTE, J. M.; Manual de indústrias de alimentos. São Paulo: Livraria Varela,1995. 600p. 
MARTINS, MC; SANTOS, LMP; ASSIS, AMO. Prevalência da hipovitaminose A em pré-escolares no Estado de Sergipe. 1998. Rev Saúde Pública. 2004; 38 (4): 53742.

MEILGAARD, M.; CIVILLE, G. V.; CARR, B. T. Sensory evaluation techniques.3 ed. New York: CRC, 1999. $281 \mathrm{p}$

MUSTONEN, L.; WALLIUS, E.; HURME, T. Nitrogen fertilization and yield formation of potato during a short growing period. Agricultural and Food Science, v.19, p.173-183, 2010.

NARAIN, N.; FERREIRA, D.S.; ARAGÃO, G.C.; ARAGÃO, W.M. Tecnologia do processamento do fruto. In: SILVA JÚNIOR, J. F.; LÉDO, A. S. A cultura da mangaba. Aracajú: Embrapa Tabuleiros Costeiros, 2006, cap. 17, p. 221-232.

PÓVOA, H.; CALLEGARO, J.; AYER L. Nutrição Cerebral. Rio de Janeiro: Objetiva, 2005. p. 107-108.

QUEIROZ, D.; PAIVA, A.A.; PEDRAZA, D.F.; CUNHA, M.A.L.; ESTEVES, G.H.; DE LUNA, J.G.; et al. Deficiência de vitamina A e fatores associados em crianças de áreas urbanas.Rev SaúdePública. 2013;47(2):248-56.

RAMALHO, RA;FLORES, H, Saunders, C. Hipovitaminose A no Brasil: um problema de saúde pública. Rev Panam Salud Publica. 2002; 12: 117-23.

RAMALHO, RA;PADILHA P, Saunders C. Análise crítica de estudos brasileiros sobre deficiência de vitamina A no grupo materno-infantil.Rev Paul Pediatr. 2008; 26: 392-9.

RANIERI, L. M.; DELANI, T. C. O. Biomassa e Ações Fisiológicas do Amido Resistente. V.20, n.3, pp.43-49 (Out - Dez 2014).

RIBEIRO, H. S.; AX, K.; SCHUBERT, H. Stability of lycopene emulsions in food systems. Journal of Food Science, 68, 2730-2734, 2003.

ROSSA, P.N. et al. Propriedades físico-químicas e reológicas de sorvetes comerciais. In: ENCONTRO DE QUÍMICA DA REGIÃO SUL, 16., 2008, Rio Branco. Anais... Rio Branco: FURB, 2008.

SOARES, J. H.; CRAFT, N. E. Relative solubility, stability, and absorptivity of lutein and b-carotene in organic solvents.Journal of Agricultural and Food Chemistry, 40, 431-434, 1992.

SOLER, M.P.; VEIGA, P.G. Sorvetes. Campinas: ITAL/CIAL, 2001. 68 p.

TOPPING, D. L.; FUKUSHIMA, M.; BIRD, A. R. Resistant starch as a prebiotic and symbiotic: state of the art. Proc of the NutrSoc, Edinburg, v. 62, n. 01, p. 171-176, 2011. 
WALKELING, I. N.; MACFIE, J. H. Designing consumer trials balanced for first and higher orders of carry-over effect when only a subset of $k$ samples from $\mathbf{t}$ may be tested. Food Quality and Preference, Oxford, v. 6, n. 4, p. 299-308, 1995.

ZEBARTH, B.J.; ROSEN, C. J. Research perspective on nitrogen BMP development for potato. American Journal of Potato Research, v.84, p.3-18, 2007. 